\title{
Estudo Mesoscópico da Valva Mitral e do seu Anel Fibroso
}

\author{
Jennecy Sales Cavalcanti, Eveline de Lucena O liveira, Emanuelle Tenório A. M. Godoi, \\ Laura Patrícia Ferreira Santos, Viviane Xavier de Lima e Silva, M icheline de Lucena O liveira \\ Recife, PE
}

\begin{abstract}
Objetivo - Estudar o arranjo espacial dos elementos fibrosos que constituem os folhetos da valva mitral e do seu anel fibroso.

Métodos - Foram utilizados 20 corações adultos, de ambos os sexos, fixados em formol a 10\%. Isolaram-se a valva mitral, juntamente como anel fibroso, e uma pequena quantidade de tecido muscular ao seu redor. Parte desse material foi incluído em parafina, submetido a cortes seriados de 40um de espessura e corados pelo tricrômio de Azan e pela resorcina-fucsina, e o restante das peças dissecadas sob lupa estereoscópica, com ajuda de delicadas pinças e agulhas, para se observar a disposição dos feixes miocárdicos ao nível do anel mitral.
\end{abstract}

Resultados - Observou-se que o anel fibroso mitral era constituído por feixes colágenos de trajetória semicircular, envolvendo de forma incompleta o óstio atrioventricular, uma vez que era ausente na região ântero-medial do óstio. Verificou-se que os feixes miocárdicos ventriculares inseriam-se de forma oblíqua, na borda externa do anel, sendo que na região ântero-medial assumiam uma trajetória semicircular. Os folhetos da valva mitral eram constituídos de feixes colágenos dispostos, paralelamente, no sentido do maior eixo da válvula, recobertos pelo endocárdio atrial e ventricular. Os feixes colágenos, presentes na base dos folhetos valvares, praticamente se continuavam com os do anel fibroso. Observou-se, em alguns casos, a existência de delgados feixes miocárdios atriais nofolheto valvar anterior, que praticamente eram restritos à região central das válvulas.

Conclusão - Os folhetos da valva mitral e seu anel fibroso possuem uma continuidade estrutural, que demonstra que estes elementos funcionam de forma integrada no fechamento do óstio atrioventricular esquerdo durante a sístole ventricular, no que seria auxiliado pela redução do diâmetro do anel fibroso, através da contração dos feixes miocárdicos semicirculares que nele se inserem.

\section{Mesoscopic Study of the Mitral Valve and its Fibrous Ring}

Purpose - To study the spatial arrangement of the fibrous elements that form the leaflets of the mitral valve and its fibrous ring.

Methods - The study of 20 human adult hearts, of both sexes, fixed in 10\% formaldehyde solution was made. The mitral valves with their fibrous rings and small parts of the adjacent atrial and ventricular muscles were removed. Part of this material was embedded in paraffin and cut serially at a thickness of $40 \mu \mathrm{m}$ and stained by Azan's trichrome and by resorcin-fuccin and another was dissected under stereoscope in order to verify the arrangement of the myocardial bundles at the level of the fibrous ring.

Results - It was observed that the fibrous ring is consisted of collagenous fibers which involved in an incomplete form the atrioventricular ostium, as they were absent in the anteromedial region of the ostium. The leaflets were made of collagenous fibers disposed parallel to the long axis of the valve. This collagenous fibers were covered by atrial and ventricular endocardium. The collagenous fibers of the leaflets were continuous, by their base, into the fibrous ring. It was observed, in a few cases, the presence of atrial muscle fibers into the anterior leaflet of the mitral, mainly in its central area.

Conclusion - The leaflets of the mitral valve and its fibrous ring have a structural continuity suggesting that elements would act synchronously in the closure of the atrioventricular ostium during ventricular systole. The contraction of the myocardial bundles fixed in the fibrous ring contributes to decrease the diameter of the mitral ring.

Key-words: mitral valve, fibrous ring, heart

Palavras-chave: valva mitral, anel fibroso, coração

Arq Bras Cardiol, volume 69 (n 4), 243-246, 1997

Centro de Ciências Biológicas - Universidade Federal de Pernambuco, Recife Correspondência: Jennecy Sales Cavalcanti - Rua Félix de Brito Melo, 912/501 51020-260 - Recife, PE

Recebido para publicação em 28/4/97

Aceito em 29/7/97
O estudo da constituição do aparelho valvar mitral é de grande interesse, pois o conhecimento de seu arranjo estrutural pode fornecer dados importantes para o entendimento mais completo sobre o funcionamento desse sistema 
como um todo, permitindo que se façam abordagens cada vez mais precisas no tratamento das diversas doenças que acometem essa valva.

O aparelho valvar mitral requer para sua competência, a integridade funcional de quatro componentes anatômicos, trabalhando coordenadamente, que são: as cúspides, o anel valvar, as cordas tendíneas e os músculos papilares. Como é sabido, a deficiência da função mitral pode resultar de causas congênitas ou adquiridas (inflamação reumática, endocardite bacteriana, infarto do miocárdio, etc) que comprometem um ou mais desses componentes.

Segundo alguns autores ${ }^{1-3}, \mathrm{o}$ anel fibroso que circunda o óstio atrioventricular esquerdo possui fibras musculares em sua constituição, que, ao se contraírem, auxiliariam no processo de fechamento da valva mitral, reduzindo a circunferência de seu anel. Outros autores descrevem, de forma sucinta, a constituição dos folhetos que formam essa valva, sem no entanto, darem um sentido de conjunto a esses elementos ${ }^{3-7}$.

Assim, revendo a literatura, verificamos que há escassez de informações sobre o arranjo dos elementos fibrosos que constituem a valva mitral, bem como seu anel, o que nos levou a estudar, em nível mesoscópico, o arranjo espacial dos elementos que formam essas estruturas, a fim de fornecer dados morfológicos de interesse à cirurgia cardíaca e à valvoplastia.

\section{Métodos}

Foram utilizados 20 corações de adultos, de ambos os sexos, brancos e não brancos, de diferentes causa mortis, sem evidências macroscópicas de valvopatias, fixados em formalina $10 \%$.

Procedeu-se a retirada dos átrios, através de incisão ao longo do sulco coronário, fez-se outra incisão ao longo da borda esquerda do coração e, com o ventrículo esquerdo aberto, retirou-se o aparelho valvar mitral, seccionando-se os músculos papilares ao nível de sua implantação na parede ventricular, isolando-se o anel fibroso e deixando uma pequena quantidade de tecido muscular ao redor dele. Esse material foi submetido a cortes panorganográficos, histológicos e preparados totais, técnicas mesoscópicas que permitem verificar o arranjo espacial dos elementos fibrosos e musculares, como se segue:

Cortes panorganográficos - esta metodologia foi aplicada a sete peças, incluídas em parafina e submetidas a cortes seriados transversais e longitudinais de $40 \mu \mathrm{m}$ de espessura e os cortes obtidos, corados pelo tricrômio de Azan e analisados por transiluminação, utilizando-se estereomicroscópio.

Cortes histológicos - neste grupo foram utilizadas seis peças, incluídas em parafina e submetidas a cortes seriados longitudinais e transversais, todas com $10 \mu \mathrm{m}$ de espessura, coradas pelos métodos da resorcina-fucsina (fibras elásticas) e tricrômio de Azan (fibras colágenas e musculares).

Preparados totais - foram utilizadas sete peças para esse método. A análise do material foi feita com ajuda de lupa estereoscópica sob epi-iluminação, por meio de minu-

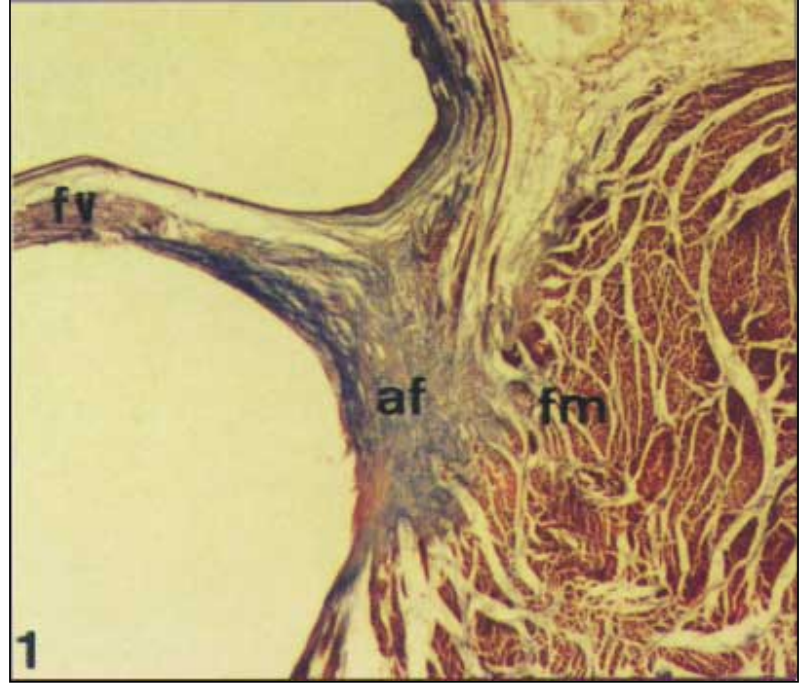

Fig. 1 - Corte transversal do aparelho valvar mitral. Observe o anel fibroso (af) e sua íntima relação com o folheto valvar (fv) e com os feixes miocárdicos (fm). Azan, 60x.

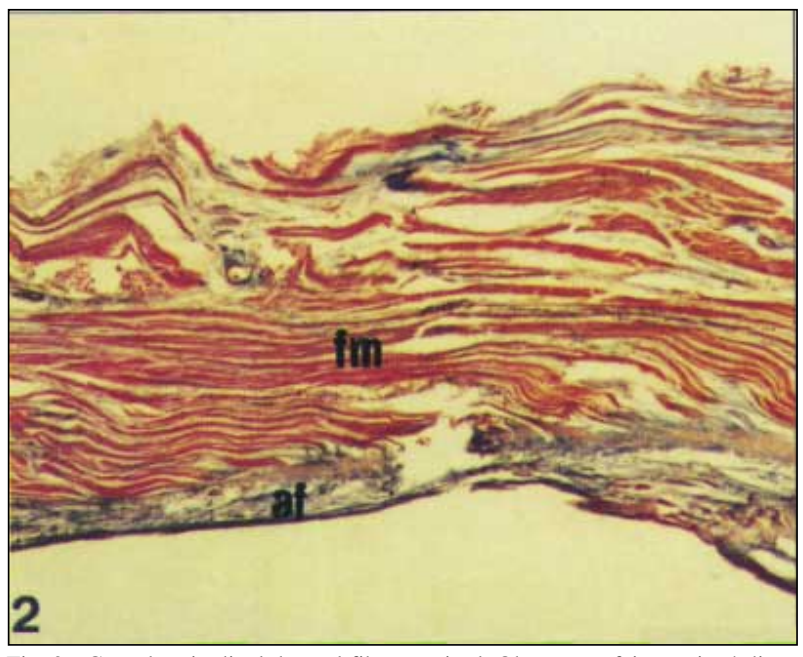

Fig. 2 - Corte longitudinal do anel fibroso mitral. Observe os feixes miocárdicos semicirculares (fm), inserindo-se no anel fibroso mitral (af). Azan, 60x.

ciosa dissecção, com ajuda de delicadas pinças e agulhas e os resultados obtidos ilustrados por meio de fotografias.

\section{Resultados}

Observamos que o anel fibroso mitral é constituído por feixes de fibra colágenas de trajetória semicircular, mostrando-se incompleto na sua parte ântero-medial, que corresponde, topograficamente, à região de continuidade mitro-aórtica. Verificamos, ainda, delgadas fibras elásticas adjacentes ao anel fibroso, presentes em maior quantidade na porção anterior do anel. $\mathrm{O}$ anel fibroso apresenta-se mais espessado na sua parte posterior, que corresponde à região de implantação do folheto mural da valva mitral, devido ao maior contingente de fibras colágenas em seu interior (fig. 1). Notamos, também, que os feixes miocárdicos inserem-se no anel fibroso, de forma inclinada, assumindo uma trajetória aproximadamente semicircular, principalmente na região ântero-medial do anel (fig. 2). 
Na região ântero-medial do óstio atrioventricular, onde inexiste o anel fibroso, os feixes miocárdicos provenientes da camada superficial da parede ventricular esquerda, assumem uma trajetória semicircular, completando o anel fibroso e servindo como limite entre a base do folheto anterior da valva mitral e o trígono intervalvar (espaço intervalvar).

Os folhetos anterior e posterior da valva mitral são constituídos, principalmente, por feixes colágenos, dispostos, paralelamente, no sentido do maior eixo das válvulas, cobertas pelo endocárdio atrial e ventricular (fig. 3). Estes feixes colágenos continuam-se no anel fibroso, constituindo, praticamente, uma única estrutura (fig. 4). Na região ântero-medial, onde o anel fibroso é incompleto, os feixes colágenos provenientes do folheto anterior da valva mitral confundem-se com os do trígono intervalvar (região mitroaórtica). Foram observadas delgadas fibras elásticas no interior dos folhetos valvares.

Verificamos a presença de feixes musculares no interior do folheto anterior da valva mitral. Estes feixes provenientes do miocárdio atrial, possuem trajetória oblíqua, tendentes a longitudinal, em relação ao maior eixo da válvula, e se estendem da base do folheto valvar até as proximidades de sua região central (fig. 4).

\section{Discussão}

Os resultados obtidos neste trabalho mostraram que, do ponto de vista estrutural, existe continuidade entre os folhetos valvares e o anel fibroso mitral, claramente demonstrada, uma vez que os feixes colágenos, principal elemento de constituição das válvulas, continuam-se no anel fibroso valvar, estando, portanto, fortemente fixada, pela sua base, a essa estrutura ${ }^{8}$.

No que diz respeito a constituição do anel fibroso mitral, verificamos que ele está formado, basicamente, por feixes colágenos de trajetória semicircular, incompleto na

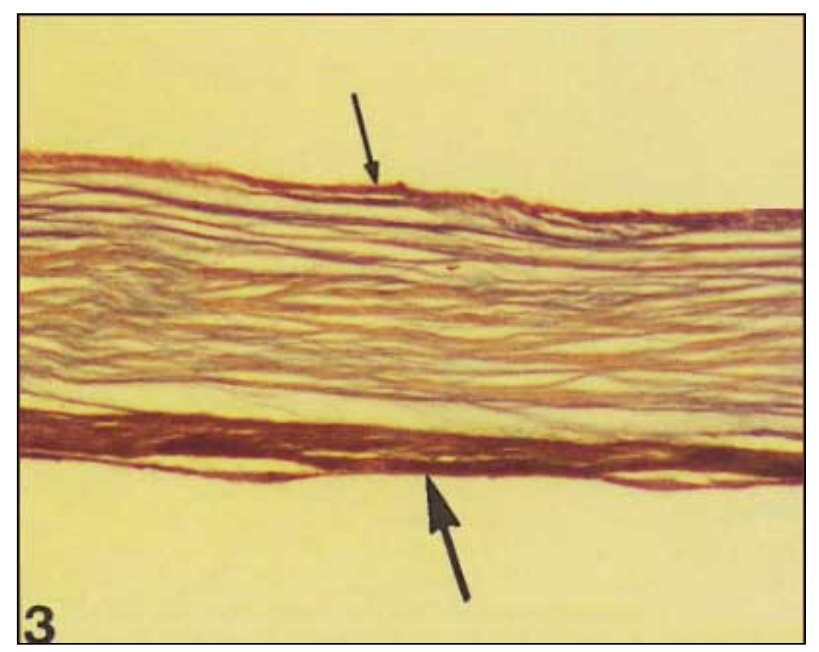

Fig. 4 - Corte longitudinal do aparelho valvar mitral. Observe a continuidade dos feixes colágenos oriundos do folheto valvar com os feixes miocárdicos ventriculares. Notem-se ainda, delgados feixes miocárdicos atriais na base do folheto valvar mitral (seta). Azan, 60x.

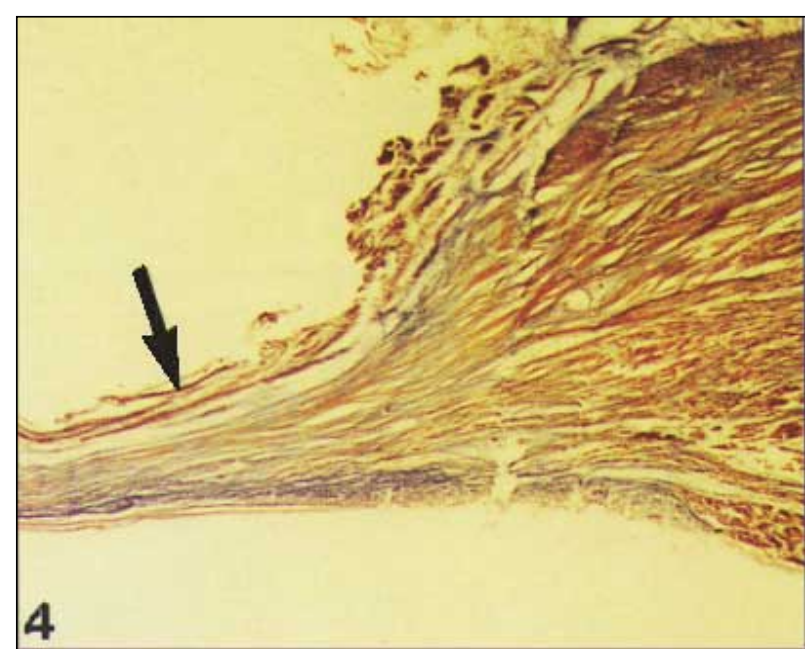

Fig. 3 - Corte longitudinal do folheto valvar mitral. Observe os feixes colágenos paralelos cobertos pelos endocárdios atrial (seta menor) e ventricular (seta maior). Azan, 120x.

região mitro-aórtica, onde parece existir uma continuidade do folheto valvar anterior com o trígono intervalvar, conforme alguns autores ${ }^{2,5,9}$. Com referência ao modo de fixação dos feixes miocárdicos no anel fibroso, observamos que ela se faz de maneira inclinada, tendendo a semicircular, principalmente, na região ântero-medial do óstio, o que nos leva a apoiar as afirmações de alguns autores ${ }^{1,3,10,11}$, ao descreverem que a circunferência do anel fibroso diminui durante a sístole cardíaca, pois esses feixes miocárdicos, ao se contraírem, teriam uma ação esfinctérica sobre o óstio atrioventricular esquerdo. Os mesmos autores referem que a redução no diâmetro do anel valvaré importante para que haja perfeita coaptação dos folhetos valvares, impedindo o refluxo sangüíneo durante a sístole ventricular. Sobre esse aspecto, alguns autores ${ }^{1,3}$ têm referido que a calcificação do anel fibroso seria um importante fator gerador de regurgitação mitral, uma vez que haveria perda da ação esfinctérica do anel valvar. Essa calcificação pode ocorrer tanto em indivíduos idosos como em pacientes jovens portadores da síndrome de Marfan ou da síndrome de Hurler. Por outro lado, podemos considerar que a dilatação excessiva do anel fibroso pode ser uma das causas de regurgitação mitral, como o que ocorre nos casos de aumento do átrio esquerdo ${ }^{3,12,13}$.

Quanto à constituição dos folhetos da valva mitral, os resultados observados são, em parte, semelhantes aos relatados na literatura ${ }^{4-6,14}$, no entanto, lembramos que os feixes colágenos, principal elemento fibroso das válvulas, dispõem-se, predominantemente, em sentido longitudinal, em relação ao seu eixo maior, de modo que as cordas tendíneas de $2^{\mathrm{a}}$ e $3^{\mathrm{a}}$ ordens cruzam perpendicularmente os feixes colágenos da válvula, formando uma espécie de rede de sustentação. Por sua vez, Tamura e $\operatorname{col}^{7}$ citam a presença de fibras elásticas no interior dos folhetos valvares e afirmam que essas fibras estão presentes em maior quantidade nas valvas mitrais prolapsadas.

Os feixes miocárdicos atriais existentes na valva mitral também foram descritos por outros autores ${ }^{15,16}$. Salienta- 
mos, no entanto, que em nosso material, os feixes miocárdicos estavam presentes, apenas, em alguns casos e eram restritos ao folheto anterior da mitral, onde podiam ser vistos, principalmente, na base da região central da válvula. Estes achados levam-nos a concordar com as afirmações de Licata ${ }^{16}$ ao descrever que essas fibras são inconstantes e sem significado fisiológico. Por outro lado, Montiel ${ }^{15}$ afirma que os feixes musculares existentes no folheto anterior da mitral não são um achado acidental e sugere que essas fibras estejam funcionalmente ligadas ao restante do miocárdio, uma vez que, segundo aquele autor, as valvas mitrais de pacientes com hipertrofia ventricular esquerda exibem uma correspondente hipertrofia dos músculos valvares. Outros autores têm relatado que a atividade atrial seja um importante fator no fechamento da valva mitral ${ }^{3,17-20}$. Ao nosso ver, estes aspectos necessitam ser mais investigados.

\section{Referências}

1. Chiechi MA, Lees WM, Thompson R-Functional anatomy of the normal mitral valve. J Thoracic Surg 1956; 32: 378-98.

2. Hirst JW - O Coração, Artérias e Veias. $4^{\mathrm{a}}$ ed. Rio de Janeiro: Guanabara Koogan, 1981; 1: 27.

3. Perloff JK, Roberts WC - The mitral apparatus: functional anatomy of mitral regurgitation. Circulation 1972; 46: 227-39.

4. Gray H - Anatomia. 29 ${ }^{\mathrm{a}}$ ed. Rio de Janeiro: Guanabara Koogan, 1977: 450-3.

5. Yoffey JM - Aparelho cardiovascular. In: Hamilton WJ, eds - Tratado de Anatomia Humana. $2^{\text {a }}$ ed. Rio de Janeiro: Interamericana, 1982: 245.

6. Moore KL - Anatomia Orientada para a Clínica. $2^{\mathrm{a}}$ ed. Rio de Janeiro: Guanabara Koogan, 1990: 79-81.

7. Tamura K, Fukuda Y, Tshizati M, Masuda Y, Yamanaka N, Ferrans VJ - Abnormalities in elastic fibers and other connective-tissue components of floppy mitral. Am Heart J 1995; 129: 1149-58.

8. Jacob MDSW, Francone CA, Lossow WI- Anatomia e Fisiologia Humanas, $5^{\text {a }}$ ed. Rio de Janeiro: Interamericana, 1984; 312.

9. Kopuz C, Erk K, Baris YS et al - Morphometry of the fibrous ring of the mitral valve. Anat Anz 1995; 177: 151-4.

10. Davis PKB - The movements of the annulus of the mitral valve. J Cardiovasc Surg 1963; 32: 378-97.
11. Smith HL, Essex HE, Baldes EG - A study of the movement of the heart valves and of the heart sounds. Ann Intern Med 1950; 33: 1351.

12. Brock RC - The surgical and pathological anatomy of the mitral valve. Br Heart J 1952; 14: 489.

13. Levy MJ, Edwards JE - Anatomy of mitral insufficiency. Progr Cardiovasc Dis 1962; 5: 119 .

14. Snell RS - Anatomia. $2^{\text {a }}$ ed. Rio de Janeiro: Médica e Científica, 1984: 75-6.

15. Montiel MM-Muscular apparatus of the mitral valve in man and its involvement in left-sided cardiac hypertrophy. Am J Cardiol 1970; 26: 341-4.

16. Licata RH-Development and structure of the cardiovascular system. In: Cardiology. An Encyclopedia of the Cardiovascular System. vol 1. New York: Mc Graw-Hill, 1961: 61-9.

17. Licata RH - Possible refluxogenic mechanisms regulating heart valve function. Rocky Mountain Med J 1967; 62: 65-8.

18. Daley RT, Mc Millan IK, Gorlin R - Mitral incompetence in experimental auricular fibrilation. Lancet 1955; 2: 18-20.

19. Mitchell M-Anatomy of the Autonomic Nervous Systems. Baltimore: Williams \& Wilkins, 1953: 356

20. Williams TH - Mitral and tricuspid valve innervation. Br Heart J 1964; 26: 10515 . 